\title{
CIRCULAR ECONOMY MODEL FOR RECYCLING WASTE RESOURCES UNDER GOVERNMENT PARTICIPATION: A CASE STUDY IN INDUSTRIAL WASTE WATER CIRCULATION IN CHINA
}

\author{
Kai-wen SHEN ${ }^{1}$, Lin $\mathrm{LI}^{2 *}$, Jian-Qiang WANG ${ }^{1 *}$ \\ ${ }^{1}$ School of Business, Central South University, Changsha 410083, PR China \\ ${ }^{2}$ School of Business, Hunan University, Changsha 410082, PR China
}

Received 19 October 2017; accepted 21 July 2019

\begin{abstract}
A circular economy (CE) is proposed to mitigate resource shortage and environmental pollution. Given the inevitable conflict between the new development mode and traditional economic benefits, practical experience shows that CE implementation needs the support of outside forces, such as government policy interventions or environmental organisations' propaganda guidance. On the basis of existing studies, the present work establishes a systematic economic model in accordance with the characteristics, objectives and principles of $\mathrm{CE}$. The equilibrium solution and critical condition of government and non-government participation models are obtained through game analysis. We select the industrial waste water circulation of some provinces in China to illustrate the feasibility and effectiveness of the proposed model. Overall, our results indicate that the gap between the critical price and unit processing cost determines the promotion of $\mathrm{CE}$ and government intervention. Moreover, government intervention is critical to building a waste management department in its early stage.
\end{abstract}

Keywords: circular economy, economic model, game analysis, equilibrium analysis.

JEL Classification: C62, O13, Q29, Q52.

\section{Introduction}

In recent years, scholars from different fields have conducted considerable research on circular economy (CE) for mitigating the environmental problem. CE has provided people with a new development mode to replace the dominant economic development mode. In the 1960s, ecological economist Boulding (1966) first proposed the concept of CE. Boulding stated that the best approach for maximising the use of limited resources is to recycle waste resources. In comparison with the traditional development model, the closed loop development mode can reduce pollution emissions and improve resource reuse rate, that is the major advantage of the CE model (Witjes \& Lozano, 2016). On the basis of the CE concept, scholars have

*Corresponding author. E-mail: Li2518@hnu.edu.cn

\#Corresponding author. E-mail: jqwang@csu.edu.cn

(C) 2019 The Author(s). Published by VGTU Press

This is an Open Access article distributed under the terms of the Creative Commons Attribution License (http://creativecommons. org/licenses/by/4.0/), which permits unrestricted use, distribution, and reproduction in any medium, provided the original author and source are credited. 
deepened the study on the basic principles that $\mathrm{CE}$ should follow. The academic community generally agrees on the 3R's principles, namely, reduce (Su, Heshmati, Geng, \& Yu, 2013; Winans, Kendall, \& Deng, 2017), reuse (Castellani, Sala, \& Mirabella, 2015) and recycle (Birat, 2015). The 3 R's principle not only pointed out the goal of circular economy in the input end, output end and process of material cycle, but also established a basic framework for the study of CE theory. Whether the concept is urban symbiosis (Dong et al., 2016) at the macro-level or clean production (Sousa-Zomer, Magalhães, Zancul, Campos, \& Cauchick-Miguel, 2018) at the micro-level, research is performed under this framework.

Since CE was proposed, countries have carried out an exploratory implementation of CE (Guo et al., 2017a; Haupt, Vadenbo, \& Hellweg, 2016). To achieve the economic function of the environment and transit to CE, many different policies are proposed (Pigou, 2014; Yong, 2007). To date, many countries, such as Germany, Japan and China, have successively formulated policies on CE. Among them, policy support in most countries is bottom-up and China's policy support is top-down (Ghisellini, Cialani, \& Ulgiati, 2016). Scholars have conducted research on the differences among various policies of countries (McDowall et al., 2017; Su, Heshmati, Geng, \& Yu, 2013). On the basis of practical experiences, enterprises are often unwilling or unable to take the initiative to change because of the economic losses caused by the transformation of the development mode (Winans, Kendall, \& Deng, 2017; $\mathrm{Wu}$, Shi, Xia, \& Zhu, 2014). Outside forces are essential for guidance and support. Other scholars have studied the necessity and effectiveness of government participation. Part of the research is the extended discussion on eliminating external uneconomic (Liu et al., 2018; Whicher, Harris, Beverley, \& Swiatek, 2018). Another part has focused on improving the CE through policies (da Silva, 2018; Liu, Liang, Song, \& Li, 2017; Marra, Mazzocchitti, \& Sarra, 2018). These studies discussed the role of the government in developing CE on the basis of an established CE system.

With the continuous development of $\mathrm{CE}$, numerous scholars are exploring $\mathrm{CE}$ from different angles. George, Lin and Chen (2015) presented a theoretical model incorporating the concept of $\mathrm{CE}$ activities and showed that environmental quality cannot be maintained or improved via economic growth. Haas, Krausmann, Wiedenhofer, and Heinz (2015) applied a sociometabolic approach to assess the circularity of global material flows and analysed the reasons for the low degree of circularity in the European Union. Bocken, de Pauw, Bakker and van der Grinten (2016) developed a framework of strategies to guide designers and business strategists in the move from a linear economy to a CE and introduced the terminology of slowing, closing and narrowing resource loops. Shen and Wang (2018) proposed a multi-criteria decision-making method to solve the regional CE development planning selection problem under the condition of incomplete information reliability. In addition, several studies focused on the analysis of economic behaviour and theory of CE (Andersen, 2007; Geissdoerfer, Savaget, Bocken, \& Hultink, 2017), supply chain management (Genovese, Acquaye, Figueroa, \& Koh, 2017; Pan et al., 2015) and dynamic growth model for resource use and recycling (Franco, 2017; Pomponi \& Moncaster, 2017). Other studies showed strong interest in the de-growth of CE (Kallis, 2011; Schneider, Kallis, \& Martinez-Alier, 2010). These studies illustrate the inherent logic of $\mathrm{CE}$ from different perspectives.

Game refers to the process of selecting and implementing a number of individuals or teams from their respective choices of behaviours or strategies under certain conditions (Ka- 
lathil, Wu, Poolla, \& Varaiya, 2017; Shubik, 1981). When we consider related waste disposal enterprises as an independent department in the circulatory system, this department forms a game relationship with the production department and the government. Many achievements have been made in using the game theory, including cooperative game (Ross, 2018), non-cooperative game (Namany, Al-Ansari, \& Govindan, 2018), and complete information game (Tan, Liu, Wu, \& Chen, 2018), to solve economic problems (van der Ploeg \& de Zeeuw, 2016; Wenxia, Yundi, \& Tianyang, 2015; Zhao et al., 2018). In the study of circular economy, Kurzban and Houser (2001) used the public goods game to show substantial individual differences in patterns of contributions to the circular public good. Zhang and Liu (2013) proposed four game theory models for the three-level green supply chain system in which market demand correlates with product green degree. Sun, Li and Wang (2019) proposed a comprehensive model using game theory and a data envelopment analysis (DEA) method to improve resource utilization efficiencies and reduce pollutant emissions in the circular economic system. These studies mainly solve the problem of the circular economy at the micro-level or at the meso-level, but lack the analysis of the integrity of the circulatory system. Few studies have explored the role of the government in the early stages of the establishment of CE system and the boundary of government participation in the process of $\mathrm{CE}$ transitioning from external interference to autonomous operation.

By drawing on existing research, the present study attempted to establish a model for analysing CE from the perspective of resource flow. Considering the different resource flow between the production department, waste management department and nature environment, this study established no recycling resource return model and recycling resource return model. In the absence of government participation, the circulatory system is established only when the production department discharges waste to the waste management department without economic loss. In view of this, this study found the boundary of government participation under the premise that the circulatory system can operate autonomously. When the circulatory system can not run independently, the government participation is necessary. The purpose of government participation is to maintain the circulatory system without adding extra burden to the production department. Based on this purpose, the boundary of government taxation can be obtained. The boundary condition of government participation is only related to three factors, namely, unit processing cost, disposal return rate and natural resource price. The boundary of government taxation is similar.

The results show that in the short run, the government can maintain the circulatory system by increasing natural resource prices or subsidies to reduce unit processing costs. In the long run, the government should focus on improving the disposal return rate and reducing the unit processing cost through technological innovation. Comparing these models, the government participation boundary of the no recycling resource return model is more lenient than that of the recycling resource return model. Although the resource flow has a significant effect on the boundaries of government participation, those of government taxation are not affected. This research selected the industrial waste water circulation data of some provinces in China to illustrate the feasibility and effectiveness of the proposed model. The obtained results show that the Chinese government's policy on industrial waste water brings the actual situation close to the boundary obtained by the proposed model. 
The contributions of this paper can be summarised as follows. First, to distinguish CE from other similar concepts and highlight its advantages, this study provided the definition of CE under the 3R's principle from the perspective of resource flow. Second, this research regarded the enterprises who undertake the task of resource recycling in the closed loop as a department with the same status as the production department. On the basis of different resource flows, this study constructed different static models considering whether the government participates or not. Third, this work obtained the boundary conditions of government participation in the process of $\mathrm{CE}$ transitioning from external interference to autonomous operation by using equilibrium analysis.

This paper is structured as follows: Section 1 (CE model) defines the connotation of CE and selects the cycle path, main variables and parameters. Section 2 (Model analysis) establishes the non-government participation and pollution tax models, performs the theoretical analysis and logical deduction and derives the critical condition and optimal solution of each model. Section 3 (Comparative analysis) presents the validity standard of the CE model and compares government to non-government participation model. Section 4 (Application of the industrial waste water circulation in China) illustrates the feasibility and effectiveness of the proposed model on the basis of data from the industrial waste water circulation of some provinces in China. The last Section (Conclusions) summarises the results of the model analysis and offers suggestions for CE development.

\section{CE model}

\subsection{Definition of Circular Economy (CE)}

Although CE research has increased in the past years, no unified definition has been recognised by the academic community because of the complexity of CE. For instance, Mckinsey Global Institute (2011) stated that "In short, it replaces a through put and efficiency driven view that ultimately degrades capital with one where capital rebuilding and maintenance offers an upward spiral or virtuous cycle, and a continuous flow of materials and products". Regardless of the definitions of CE, the resource flow and "3R's principle" are always the core content. In the CE model, resources have different statuses in varied stages. The mutual transition among different states of resources realises the resource flow to link the economic system with environmental system. This feature is the most significant difference between CE and other similar concepts, such as ecological economy and low-carbon economy.

This study considers that as a new economic development mode, CE must restructure and upgrade the economic system in accordance with the law of material circulation and energy flow in the natural ecological system. Moreover, CE must explore the new style of economic increase to synchronise the growth of economic and environmental benefits and extend the use cycle and use of resources to achieve sustainable development (Ghisellini, Cialani, \& Ulgiati, 2016; Pitt, \& Heinemeyer, 2015; Preston, 2012).

\subsection{Cycle path selection}

On the basis of the 3R's principle, scholars have studied CE from three levels, namely, meso-, macro- and micro-levels. At the meso- and macro-levels, research focused on eco-industrial 
parks (Wen \& Meng, 2015), urban symbiosis (Tukker, 2015) and so on. At the micro-level, research focused on the green individual behaviour, such as cleaner production (Leslie, Leonards, Brandsma, Boer, \& Jonkers, 2016) or green consumption (Wong \& Zhou, 2015), for the single enterprise or consumer. The model established in this study is mainly reflected at the micro-level and does not involve the discussion of meso- and macro-levels. We considered a four-department economic system, which includes the production department, waste management department, consumer market and government. The waste management department is mainly responsible for collecting and processing waste resources from the production department and consumer market. Allowing resource flow to pass through a waste management department is a symbol of the establishment of the CE system.

The recycling process can be defined from three aspects, namely, waste source, treatment way and resource whereabouts. In this study, waste resources mainly come from production and consumption processes. The same recycling resources are returned to the production and consumption processes. Recycling can be divided into regeneration and reuse. Regeneration refers to waste that can regain production and consumption functions after recycling. Reuse indicates the reasonable treatment and distribution of waste to maximise waste value.

Waste resources generated during consumption are negligible compared with waste produced during production. Rarely are waste resources generated by the production process returned to the consumption process after regeneration. The path wherein the waste resources produced via the production process return to the consumption process after reuse is often aimed at energy. Hence, the model established in this study is aimed at the remaining path. Figure 1 shows its circulation mode.

The arrows in Figure 1 represent the possible resource flow between departments. As different forms of resources flow between different departments, their flow patterns are varied. For example, when resources flow from the production department to the consumer market, the form of its expression is product; thus, its flow pattern is "produce". When resources flow from the production department to the waste management department, the form of its expression is waste; thus, its flow pattern is "discard".

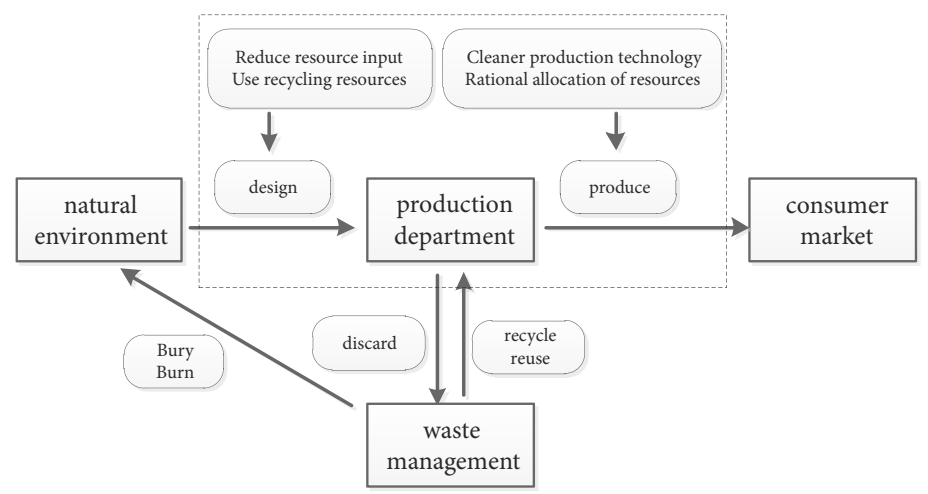

Figure 1. Micro-level 


\subsection{Parameters and variables}

In the proposed model, the two main research subjects are called production department $A$ and waste management department $B$, and the other three assistant research subjects are called the natural environment, consumer market and government. The model focuses on the flow and use of resources, in which we assume that the price of natural resources is $P_{N}$.

For production department $A$, the main objective is to select the beneficial maximisation plan from the existing production plans. To simplify the model, this study only considers the core resources of product needs. Table 1 shows the production department-related parameters of the model.

For waste management department $B$, the function is to recycle and dispose of waste resources from the production department and simultaneously adjust the circulation plan in accordance with the production plan of the production department. Table 2 shows the waste management department-related parameters of the model.

Table 3 shows the parameters and basic quantitative relations for the consumer market and government.

Table 1. Production department-related parameters

\begin{tabular}{|c|l|c|}
\hline Parameters & \multicolumn{1}{|c|}{ Meaning } & Variable constraints \\
\hline$Q$ & Product quantity & $Q>0$ \\
\hline$N$ & Used resource quantity & $N>0$ \\
\hline$\alpha$ & Production efficiency & $C_{1} \geq 0$ \\
\hline$C_{1}$ & Unit production cost & $P_{1} \geq 0$ \\
\hline$P_{1}$ & Unit product price & $I_{A} \geq 0$ \\
\hline$I_{A}$ & Gross income of production department $A$ & $C_{A} \geq 0$ \\
\hline$C_{A}$ & Gross cost of production department $A$ & $R_{A}=I_{A}-C_{A}$ \\
\hline$R_{A}$ & Gross profit of production department $A$ & \\
\hline
\end{tabular}

Table 2. Waste management department-related parameters

\begin{tabular}{|c|l|c|}
\hline Parameters & \multicolumn{1}{|c|}{ Meaning } & Variable constraints \\
\hline$P_{2}$ & Unit recycling price & $P_{2} \geq 0$ \\
\hline$C_{2}$ & Unit processing cost & $C_{2} \geq 0$ \\
\hline$\beta$ & Disposal return rate & $0 \leq \beta \leq 1$ \\
\hline$I_{B}$ & Gross income of waste management department $B$ & $I_{B} \geq 0$ \\
\hline$C_{B}$ & Gross cost of waste management department $B$ & $C_{B} \geq 0$ \\
\hline$R_{B}$ & Gross profit of waste management department $B$ & $R_{B}=I_{B}-C_{B}$ \\
\hline
\end{tabular}


Table 3. Other parameters and basic quantitative relations

\begin{tabular}{|c|l|c|}
\hline Parameters & \multicolumn{1}{|c|}{ Meaning } & Variable constraints \\
\hline$a$ & Absolute demand & $a>0$ \\
\hline$b$ & Sensitivity of market demand to price & $b>0$ \\
\hline$Q$ & Product quantity & $t_{1}>0$ \\
\hline$t_{1}$ & Pollution tax & $P_{1}$ \\
\hline
\end{tabular}

\section{Model analysis}

The models are divided into two categories on the basis of whether or not the waste management department returns the recycling resource after disposal. The first category is the no recycling resource return model. The second category is the recycling resource return model. Firstly, this study constructed a corresponding model of non-government participation and found the boundary of government participation under the premise that the circulatory system can operate autonomously. Then, this research developed the government participation model in the case that the boundary conditions are not met. With the goal that the circulatory system can still operate, the boundary of government taxation can be obtained at this time. Figure 2 presents the relationship between the models in this section.

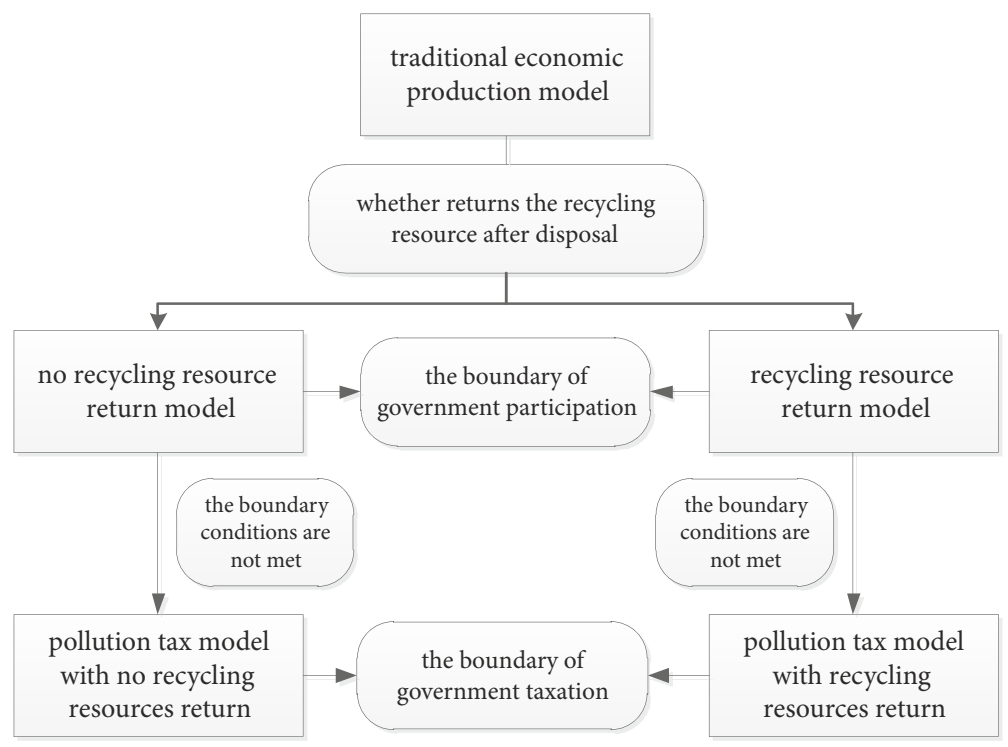

Figure 2. Relationship between the models

\subsection{Non-government participation model}

The traditional economic production model pursues the maximisation of benefits by consuming a large amount of resources. This approach leads to considerable resource waste and environment deterioration. Figure 3 presents the traditional economic production model path. 


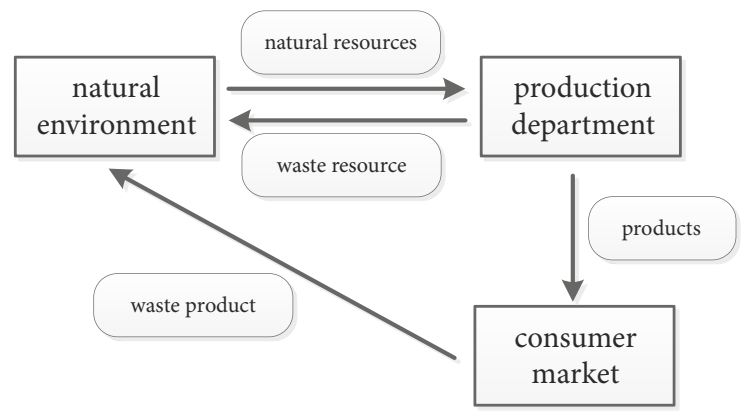

Figure 3. Traditional economic production model

The CE model must enable the resources to flow through the waste management department. Hence, the production department should opt to discharge waste resources from production process to the waste management department instead of directly discharging to the natural environment. The three ways to achieve this goal are as follows: to require the production sector to pay the cost of outside activities, improve the benefits of recycling resource, and implement free disposal of waste resources. The last two ways are more likely to be achieved than the first way in the absence of government participation. Depending on the different resource flows, the two different models are presented in the subsequent sections.

\subsubsection{No recycling resource return model}

If the waste management department does not collect any fees for the disposal of waste resources to the production department, then the production department will discharge the wastes to the waste management department without loss of economic interests. For the production department, the production behaviour is not affected. For the waste management department, the only income is from the proceeds of the sale of circular resources. Figure 4 shows the model path when the waste management department does not return the processed recycling resources to the production department.

As a result, the functions of the entire system are as follows:

$$
\begin{aligned}
& R_{A}=Q P_{1}-\frac{Q}{\alpha} P_{N}-C_{1} Q, \\
& R_{B}=(1-\alpha) \beta N P_{N}-(1-\alpha) N C_{2} .
\end{aligned}
$$

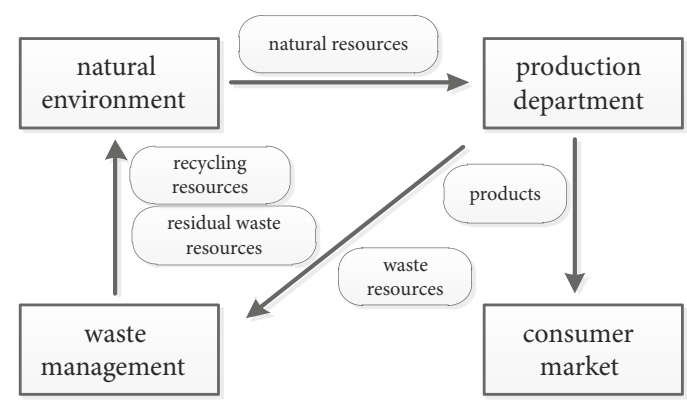

Figure 4. No recycling resource return model 
Then, we derive the equilibrium solution of maximising the benefit of the production department:

$$
\begin{aligned}
& P_{11}^{*}=\frac{a}{2 b}+\frac{P_{N}+\alpha C_{1}}{2 \alpha} ; \\
& Q_{1}^{*}=\frac{a}{2}-\frac{b P_{N}}{2 \alpha}-\frac{b C_{1}}{2} ; \\
& N_{1}^{*}=\frac{a}{2 \alpha}-\frac{b P_{N}}{2 \alpha^{2}}-\frac{b C_{1}}{2 \alpha} .
\end{aligned}
$$

As $P_{N}$ is a fixed value, the basic establishment condition of the waste management department is $R_{B} \geq 0$, i.e.

$$
C_{2} \leq \beta P_{N}
$$

We call $\beta P_{N}$ as the critical price of the no resource return model.

In practical problems, this model often corresponds to the situations in which the enterprise cannot independently assume the production and circulation or independently assume what is not in line with economic benefits. A classic example is the recycling of industrial waste water (Geng et al., 2014; Geng, Zhang, Cote, \& Qi, 2008). Factories often discharge large amounts of industrial waste water from their industrial production. In accordance with the degree of waste water pollution, industrial waste water treatment has different ways. If the pollution is lighter, then the industry may select without or only the necessary treatment and reuse the waste water in the production process. If the pollution is heavy, then the necessary pre-treatment in the factory will be selected along with the domestic sewage for further processing. The second treatment is common. Similarly, the proposed model can also be applied to waste paper (Nizami et al., 2017), waste printed circuit boards (Huang, Guo, $\& \mathrm{Xu}, 2009)$ and so on.

\subsubsection{Recycling resource return model}

If the waste management department collects fees for the disposal of waste resources, but does not return the recycling resources to the production department, or the benefits of recycling resources cannot compensate for the disposal cost of waste resources, then the production department will not opt the cycle path that will lead to loss of economic benefits. Therefore, this cycle model can be established only when the waste management department returns the recycling resources to the production department and the benefits of recycling resources can at least compensate for the cost. Figure 5 presents the recycling resource return model.

The functions of the entire system are as follows:

$$
\begin{aligned}
& R_{A}=\alpha N P_{1}+(1-\alpha) N \beta P_{N}-N P_{N}-\alpha N C_{1}-(1-\alpha) N P_{2}, \\
& R_{B}=(1-\alpha) N P_{2}-(1-\alpha) N C_{2} .
\end{aligned}
$$

In the same steps, we can derive the equilibrium solution of the entire system to obtain the maximum benefit:

$$
P_{12}^{*}=\frac{a}{2 b}-\frac{1-\alpha}{2 \alpha} \beta P_{N}+\frac{P_{N}}{2 \alpha}+\frac{C_{1}}{2}+\frac{1-\alpha}{2 \alpha} C_{2}
$$




$$
\begin{aligned}
& Q_{2}^{*}=\frac{a}{2}+\frac{1-\alpha}{2 \alpha} \beta b P_{N}-\frac{b P_{N}}{2 \alpha}-\frac{b C_{1}}{2}-\frac{1-\alpha}{2 \alpha} b C_{2} ; \\
& N_{2}^{*}=\frac{a}{2 \alpha}+\frac{1-\alpha}{2 \alpha^{2}} \beta b P_{N}-\frac{b P_{N}}{2 \alpha^{2}}-\frac{b C_{1}}{2 \alpha}-\frac{1-\alpha}{2 \alpha^{2}} b C_{2} .
\end{aligned}
$$

To achieve the situation when the overall system realises maximum benefit, the production department can maximise its interests, then we can obtain $P_{2}=C_{2}$, i.e. $R_{B}=0$. At this point, the benefit of recycling resources is $R_{r}=(1-\alpha) \beta N\left(P_{N}-P_{2}\right)$. To ensure that the production department at least has no economic losses, $\Delta R=(1-\alpha) \beta N\left(P_{N}-P_{2}\right)-(1-\alpha) N P_{2} \geq 0$ must be met. Therefore, the necessary condition of this model is $\frac{P_{N}}{P_{2}} \geq \frac{1}{\beta}+1$, i.e.

$$
C_{2} \leq \frac{\beta}{\beta+1} P_{N}
$$

We call $\frac{\beta}{\beta+1} P_{N}$ the critical price of resource return model.

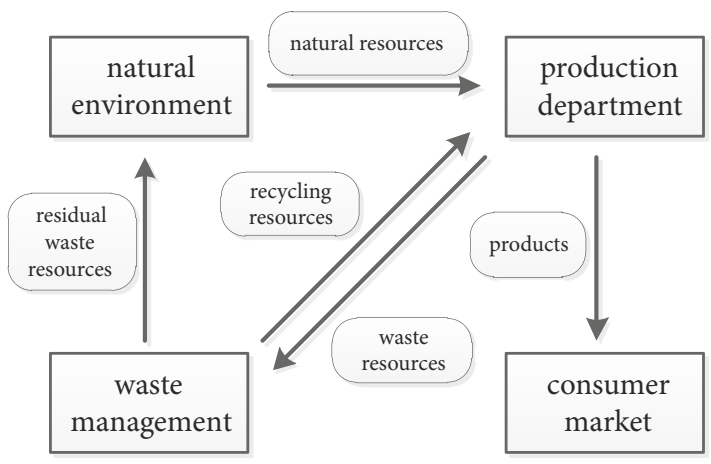

Figure 5. Recycling resource return model

In practical problems, this model often corresponds to the situations that the enterprise can independently assume the production and circulation. A classic example is the recycling of scrap steel (Wübbeke \& Heroth, 2014; Wei-guang \& Yue, 2011). The scrap steel produced in the production and processing of steel products comprises mainly of the cutting head, tail and leftover material of steel. At this point, a reasonable and effective approach is to recover, smelt and forge the scrap steel to obtain a new steel material for production. Similarly, the proposed model can also be applied to plastic waste (Huysman, De Schaepmeester, Ragaert, Dewulf, \& De Meester, 2017), leather waste (Hu et al., 2011) and so on. This cycle treatment process can bring high economic and ecological benefits.

\subsection{Government participation model}

On the basis of the abovementioned two models, the most basic condition that the cycle model without government participation should meet is $C_{2} \leq \beta P_{N}$ or $C_{2} \leq \frac{\beta}{\beta+1} P_{N}$. When $C_{2}>\beta P_{N}$ and $C_{2}>\frac{\beta}{\beta+1} P_{N}$, the market mechanism cannot achieve CE alone; thus, government participation is necessary. 


\subsubsection{Pollution tax model without recycling resource return}

As $C_{2}>\beta P_{N}$, the waste management department cannot dispose the waste resources of the production department for free. The waste management department should compensate for the loss by charging a fee. At this time, to avoid economic losses, the production department will discharge the waste directly to the natural environment. Therefore, government participation is vital. Figure 6 shows the path of the pollution tax model without recycling resource return.

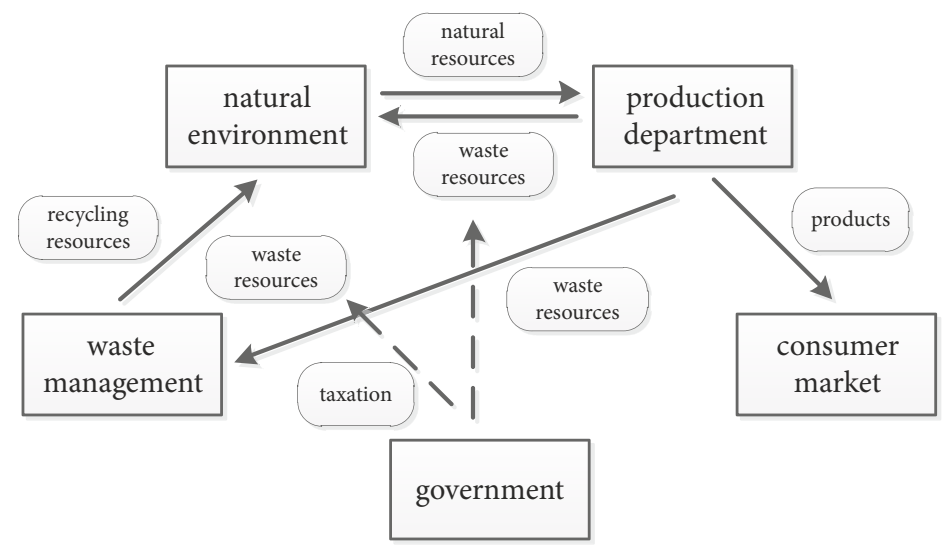

Figure 6. Pollution tax model without recycling resource return

The production department has two options in the case of pollution tax collection. One option is to pay the pollution tax directly. The other option is to shift the burden of pollution taxes to the waste management department by paying a certain fee. Clearly, the production department will select the option with less economic loss. Hence, the gross profit function of the production department is as follows:

$$
R_{A}=\left\{\begin{array}{ll}
\alpha N P_{1}-N P_{N}-\alpha N C_{1}-(1-\alpha) N t_{1}, & t_{1}<P_{2} \\
\alpha N P_{1}-N P_{N}-\alpha N C_{1}-(1-\alpha) N P_{2}, & t_{1} \geq P_{2}
\end{array} .\right.
$$

To determine the value of $t_{1}$, assuming that the production department will discharge all waste resources to the waste management department, the revenue function of the waste management department is as follows:

$$
R_{B}=(1-\alpha) N P_{2}-(1-\alpha) N C_{2}+(1-\alpha) N \beta P_{N}-(1-\alpha)(1-\beta) N t_{1} .
$$

The condition that waste management department can exist is $R_{B} \geq 0$, i.e. $P_{2} \geq C_{2}-\beta P_{N}+$ $(1-\beta) t_{1}$. Thus, we have $t_{1} \geq P_{2} \geq C_{2}-\beta P_{N}+(1-\beta) t_{1}$. After simplification, the following is obtained:

$$
t_{1} \geq \frac{1}{\beta} C_{2}-P_{N}>0 \text {. }
$$
Taking the critical tax rate in this model, $t_{1}=P_{2}=\frac{1}{\beta} C_{2}-P_{N}$. The equilibrium solution
of maximising the benefit is as follows:

$$
P_{13}^{*}=\frac{a}{2 b}+\frac{P_{N}+C_{1}}{2}+\frac{1-\alpha}{2 \alpha \beta} C_{2} ;
$$




$$
\begin{aligned}
& Q_{3}^{*}=\frac{a}{2}-\frac{b P_{N}+b C_{1}}{2}-\frac{1-\alpha}{2 \alpha \beta} b C_{2} ; \\
& N_{3}^{*}=\frac{a}{2 \alpha}-\frac{b P_{N}+b C_{1}}{2 \alpha}-\frac{1-\alpha}{2 \alpha^{2} \beta} b C_{2} .
\end{aligned}
$$

Assume that $t_{1}$ does not take the critical value, but takes a value greater than the critical value, i.e. $t_{1}^{\prime}=\frac{1}{\beta} C_{2}-P_{N}+\Delta t$, where $\Delta t$ is the deviation value and $\Delta t>0$. Then, we have $P_{2} \geq \frac{1}{\beta} C_{2}-P_{N}+(1-\beta) \Delta t$. In such a situation, the revenue functions of the production and waste management departments are as follows, respectively:

$$
\begin{aligned}
& R_{A}^{\prime}=\alpha N P_{1}-N P_{N}-\alpha N C_{1}-(1-\alpha) N P_{2} ; \\
& R_{B}^{\prime}=(1-\alpha) N P_{2}-\frac{1-\alpha}{\beta} N C_{2}+(1-\alpha) N P_{N}-(1-\alpha)(1-\beta) N \Delta t .
\end{aligned}
$$

Meanwhile, $R_{B}^{\prime} \geq 0$ is possible. The above formula shows that tax increases will not worsen the economic returns of the waste management department. The entire economic return is $R^{\prime}=\alpha N P_{1}-\alpha N P_{N}-\alpha N C_{1}-\frac{1-\alpha}{\beta} N C_{2}-(1-\alpha)(1-\beta) N \Delta t$. Thus, $R^{\prime}-R=$ $-(1-\alpha)(1-\beta) N \Delta t<0$. The higher the amount of tax collection, the greater the economic loss of the entire system.

Assuming that the tax is fixed and the processing cost of the waste management department is higher than the critical value, i.e.

$$
P_{2}=\frac{1}{\beta} C_{2}-P_{N}+(1-\beta) \Delta t+\Delta P,
$$

where $\Delta P$ is the deviation value and $0<\Delta P \leq \beta \Delta t$. Thus, the revenue function of the waste management department is as follows:

$$
R_{B}^{\prime}=(1-\alpha) N\left[P_{2}-\frac{1}{\beta} C_{2}+P_{N}-(1-\beta) \Delta t\right]=(1-\alpha) N \Delta P>0 .
$$

An increase in $P_{2}$ does not affect economic benefits of entire system. As a result, the output of production department remains unchanged, but the economic benefits will be reduced. On the basis of the previous analysis, when $t_{1}$ and $P_{2}$ take the critical value, the economic benefit of the entire system is considerable.

Corresponding to the example of industrial waste water in Section 2.1.1, at present, most countries have higher unit waste water treatment costs than unit industrial water prices. Therefore, the no recycling resource return model cannot be established. To compensate for the economic losses, the waste water treatment department will charge the production department. At this time, to ensure that the production department does not arbitrarily discharge waste water and the waste management department has no economic losses, the government will levy water pollution tax on waste water by adjusting the tax rate to establish the pollution tax model without recycling resources.

\subsubsection{Pollution tax model with recycling resource return}

For $C_{2}>\frac{\beta}{\beta+1} P_{N}$, Figure 7 shows the model path wherein the waste management department returns the recycling resources to the production department. 


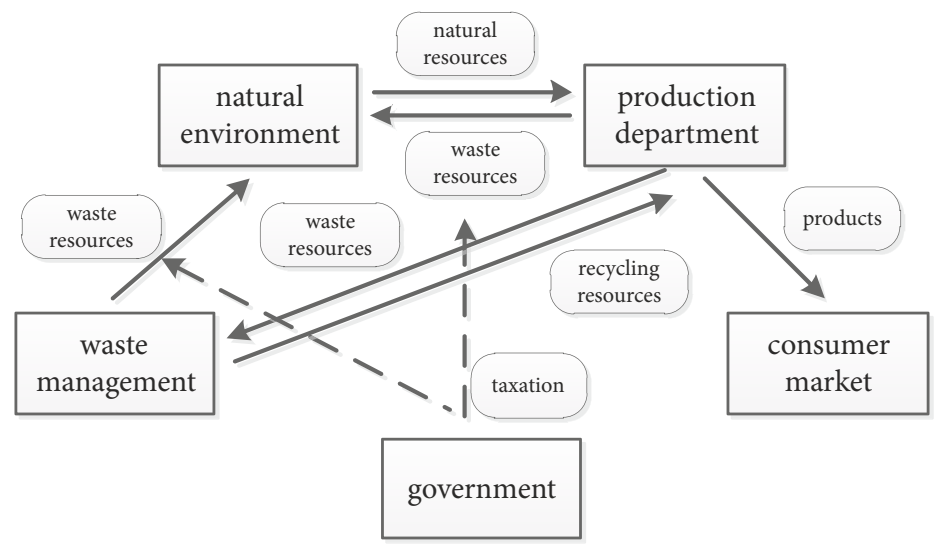

Figure 7. Pollution tax model with recycling resource return

Similar to Section 2.2.1, the revenue functions of the entire system are as follows:

$$
\begin{aligned}
& R_{A}= \begin{cases}\alpha N P_{1}-N P_{N}-\alpha N C_{1}-(1-\alpha) N t_{1}, & t_{1}<P_{2}-\beta P_{N} \\
\alpha N P_{1}-N P_{N}-\alpha N C_{1}-(1-\alpha) N P_{2}+(1-\alpha) \beta N P_{N}, & t_{1} \geq P_{2}-\beta P_{N}\end{cases} \\
& R_{B}=(1-\alpha) N P_{2}-(1-\alpha) N C_{2}-(1-\alpha)(1-\beta) N t_{1} .
\end{aligned}
$$

On the basis of $R_{B} \geq 0$ and $t_{1} \geq P_{2}-\beta P_{N}, t_{1} \geq \frac{1}{\beta} C_{2}-P_{N}$, taking critical values that $t_{1}=\frac{1}{\beta} C_{2}-P_{N}$ and $P_{2}=\frac{1}{\beta} C_{2}-(1-\beta) P_{N}$.

Whether waste management department returns resources does not affect the equilibrium solution of the entire system. A comparison of the two cases shows that, when the waste management department returns resources to the production department, the latter will compensate for the cost because of the benefits of recycling resources. However, due to the loss of revenue from recycling resources, the waste management department will transfer the loss to the production department by collecting the cost of processing fees. Thus, the final equilibrium solutions show no difference. In comparison with the pollution tax model without recycling resources, this model often corresponds to the situations wherein the enterprise can independently assume the production and circulation.

\section{Comparative analysis}

\subsection{Comparison criterion}

On the basis of the previous analysis, in this section, the benefit of the economic system is the sum of the profits between the production and waste management departments. The resources and environmental benefits are reflected in the number of reductions of the original resource consumption and directly discharged waste.

Assuming that $N$ is the original resource consumption, $M$ is the direct discharge of waste resources, function $E=F(N, M)$ is the resource environment efficiency function and

$$
\frac{\partial E}{\partial N}<0 ; \frac{\partial E}{\partial M}<0 ; \frac{\partial E}{\partial H}<0
$$


The smaller the $N$ and $M$, the greater the efficiency of the resources and environment. However, the specific expression of the resource environment efficiency function varies in accordance with different resources and evaluation criteria.

If the recycling path increases the economic and resource environmental benefits, then the system will not need external interference to exist directly. Thus, this recycling model is absolutely effective. If the recycling path reduces the economic benefit, the resource environmental benefit increases when the sum of the economic and the resource environmental benefits is not less than the traditional path. Hence, this recycling model is relatively effective. If the economic benefit is decreased and the increase of resource and environment benefit cannot compensate for the loss of economic benefit, then the model is ineffective. If the recycling path cannot increase the resources and environmental benefits, regardless of whether economic efficiency has increased, then the model remains absolutely invalid.

\subsection{Comparing with non-government participation model}

The two non-government participation models are selected as the reference value. In the no resource return model, we have

$$
\begin{aligned}
& R_{1}=Q_{1}^{*} P_{11}^{*}-\frac{Q_{1}^{*}}{\alpha} P_{N}-Q_{1}^{*} C_{1}+(1-\alpha) \beta N_{1}^{*} P_{N}-(1-\alpha) N_{1}^{*} C_{2} ; \\
& N_{1}=N_{1}^{*} ; \\
& M_{1}=(1-\alpha)(1-\beta) N_{1}^{*} .
\end{aligned}
$$

The benefit of the entire system is $D_{1}=R_{1}+E_{1}$. In the resource return model, we have

$$
\begin{aligned}
& R_{2}=Q_{2}^{*} P_{12}^{*}+(1-\alpha) \beta N_{2}^{*} P_{N}-N_{2}^{*} P_{N}-Q_{2}^{*} C_{1}-(1-\alpha) N_{2}^{*} C_{2} ; \\
& N_{2}=(1-\beta+\alpha \beta) N_{2}^{*} ; \\
& M_{2}=(1-\alpha)(1-\beta) N_{2}^{*} .
\end{aligned}
$$

The benefit of the entire system is $D_{2}=R_{2}+E_{2}$.

As in the case of the government imposing pollution tax, regardless of whether the waste management department returns resources to the production department, the equilibrium solutions that entire system finally reaches are not different. Thus, we only consider one of them. When the government collects pollution tax without recycling resources, we have

$$
\begin{aligned}
& R_{3}=Q_{3}^{*} P_{13}^{*}-Q_{3}^{*} P_{N}-Q_{3}^{*} C_{1}-\frac{1-\alpha}{\beta} N_{3}^{*} C_{2} ; \\
& N_{3}=N_{3}^{*} ; \\
& M_{3}=(1-\alpha)(1-\beta) N_{3}^{*} .
\end{aligned}
$$

The benefit of the entire system is $D_{3}=R_{3}+E_{3}$. By comparing the equilibrium solutions of models 1 and 3, we have

$$
\begin{aligned}
& Q_{3}^{*}-Q_{1}^{*}=\frac{b P_{N}}{2 \alpha}-\frac{b P_{N}}{2}-\frac{1-\alpha}{2 \alpha \beta} b C_{2}, \\
& P_{13}^{*}-P_{11}^{*}=\frac{P_{N}}{2}-\frac{P_{N}}{2 \alpha}+\frac{1-\alpha}{2 \alpha \beta} C_{2} .
\end{aligned}
$$


By comparing the two system efficiencies, we have

$$
\begin{aligned}
& R_{3}-R_{1}=\frac{1-\alpha-\beta}{\beta}\left(\beta P_{N}-C_{2}\right) N_{1}^{*}, \\
& N_{3}-N_{1}=\frac{b P_{N}}{2 \alpha^{2}}-\frac{b P_{N}}{2 \alpha}-\frac{1-\alpha}{2 \alpha^{2} \beta} b C_{2}=\frac{1-\alpha}{2 \alpha^{2} \beta} b\left(\beta P_{N}-C_{2}\right)<0, \\
& M_{3}-M_{1}=(1-\alpha)(1-\beta)\left(N_{3}-N_{1}\right)<0 .
\end{aligned}
$$

If $\alpha+\beta \geq 1$, then $R_{3} \geq R_{1}$ and $E_{3}>E_{1}$. Hence, this recycling mode is absolutely effective. If $\alpha+\beta<1$, then $R_{3}<R_{1}$ and $E_{3}>E_{1}$. We cannot, however, determine if taking this model would be effective for the entire system. When the production and waste management departments choose this path under the restriction of government policy, even if the economic benefit is negative, this cycle model remains effective. In the case of no growth in economic efficiency, the government forces the production department to discharge waste resources to the waste management department by collecting pollution tax. This strategy could only solve the problem that the production department has no motivation to change the development model. However, the model does not have the capability of development in the long run.

By comparing the situations of models 2 and 3, we have

$$
\begin{aligned}
& N_{3}-N_{2}=(1-\alpha) \beta N_{1}^{*}-\frac{1-\alpha}{2 \alpha^{2} \beta} b\left(1-\beta+\beta^{2}-\alpha \beta^{2}\right)\left(C_{2}-\beta P_{N}\right), \\
& M_{3}-M_{2}=(1-\alpha)(1-\beta)\left(N_{3}-N_{2}\right)=\frac{(1-\alpha)^{2}(1-\beta)^{2} b}{2 \alpha^{2} \beta}\left(\beta P_{N}-C_{2}\right)<0 .
\end{aligned}
$$

Assume that the natural resource consumption function is $f(\Delta n)=a_{0}-b_{0} \Delta n$, where $a_{0}=(1-\alpha) \beta N_{1}^{*}>0, \quad b_{0}=\frac{1-\alpha}{2 \alpha^{2} \beta} b\left(1-\beta+\beta^{2}-\alpha \beta^{2}\right)>0$ and $\Delta n=C_{2}-\beta P_{N}>0 . \quad f(\Delta n)$ is monotonically decreasing. When $C_{2}=\beta P_{N}, f(\Delta n)=a_{0}>0$. With the increasing of $\Delta n$, $f(\Delta n)$ is transferred from positive to negative. Therefore, only when $\Delta n$ is sufficiently large, would model 3 be effective compared with model 2 .

\section{Application of the industrial waste water circulation in China}

On the basis of the analysis in Section 2, the quantitative relationship between the unit processing cost and critical price is the decisive factor for determining the development model of $\mathrm{CE}$ and the degree of government intervention. Therefore, in practical application, we should initially determine the quantitative relationship among $C_{2}, \beta$ and $P_{N}$. Then, in accordance with the actual situation, we formulate corresponding policies and measures to make $C_{2}, \beta$ and $P_{N}$ meet the ideal conditions for the development of CE. Since the late 1970s, China has experienced remarkable economic growth because of its opening to the outside world. However, such rapid development brought serious environmental problems (Yuan, Bi, \& Moriguichi, 2010). The traditional linear economic development model has been difficult to sustain in China. Therefore, to alleviate the environmental pressure and explore a new development model, Chinese scholars have conducted a comprehensive study of CE (Geng, Fu, Sarkis, \& Xue, 2012; Guo, Geng, Sterr, Zhu, \& Liu, 2017b; Su, Heshmati, Geng, \& Yu, 2013). 
China's attempt to develop CE has greatly enriched the connotation of CE and provided valuable experience for its development worldwide. Moreover, China is paying more attention to the regulatory role of the government in economic development than other countries. In this section, we select the industrial waste water circulation of certain provinces in China as an example to illustrate the feasibility and effectiveness of the proposed model.

\subsection{Case study}

Without losing generality, this study selected eight regions for analysis, including Hunan and Sichuan Provinces. Table 4 shows the emission and treatment of industrial waste water in the selected regions from 2013 to 2015.

We can use the ratio of the difference between discharged and treated volumes to the treated volume as the approximation of disposal return rate $(\beta)$ of industrial waste water. Figure 8 shows the disposal return rates of industrial waste water in the selected regions.

As processing technology, emission standards and geographical locations vary from region to region, the average cost of industrial waste water treatment is also different in each region (Tan et al., 2015). Jiangsu, Zhejiang and Anhui Provinces have higher emission standards than other provinces, and thus their average cost is higher than that of other provinces. The eastern region is generally more economically developed than the central and western regions in China. Hence, the cost of resource utilisation is relatively high, such as construction land, labour, material costs, etc. This costs difference leads to a slightly higher average cost of governance in the eastern region than in other regions. Figure 9 shows the average costs of industrial waste water treatment in the selected regions.

Since 2007, most provinces in China have begun to levy sewage treatment fees. Enterprises that pay sewage treatment fees no longer need to pay sewage charges. The sewage charges are collected after discharge of waste water. The sewage treatment fees are levied at the same time as the base water fee. Each province determines the price of industrial water in accordance with its situation. Table 5 shows the price of industrial water in the selected regions.

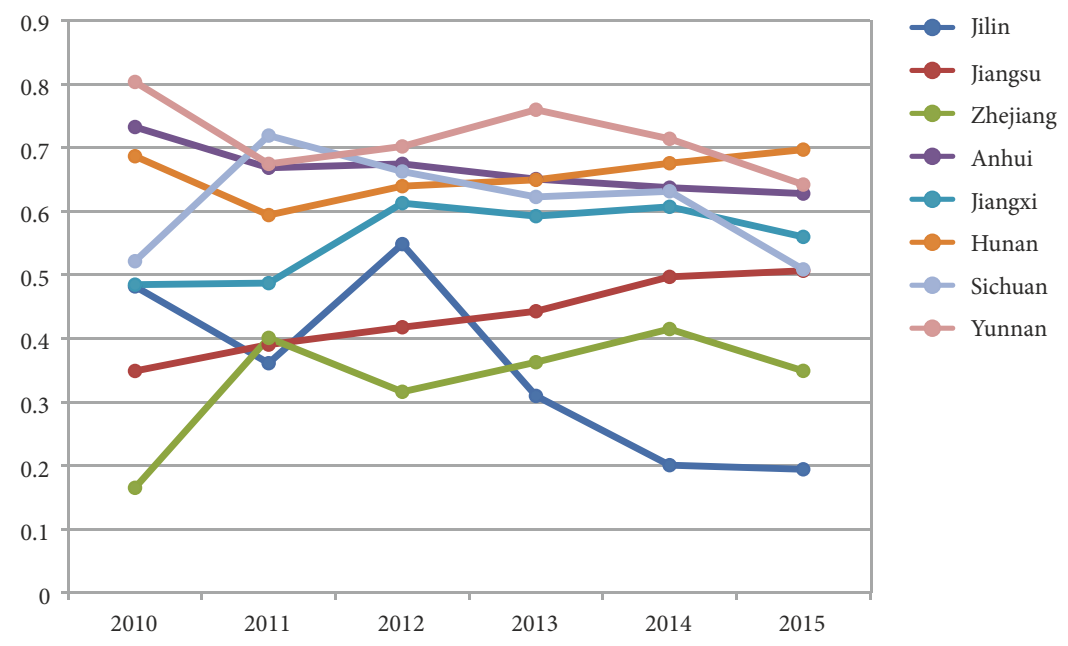

Figure 8. Disposal return rates of industrial waste water 


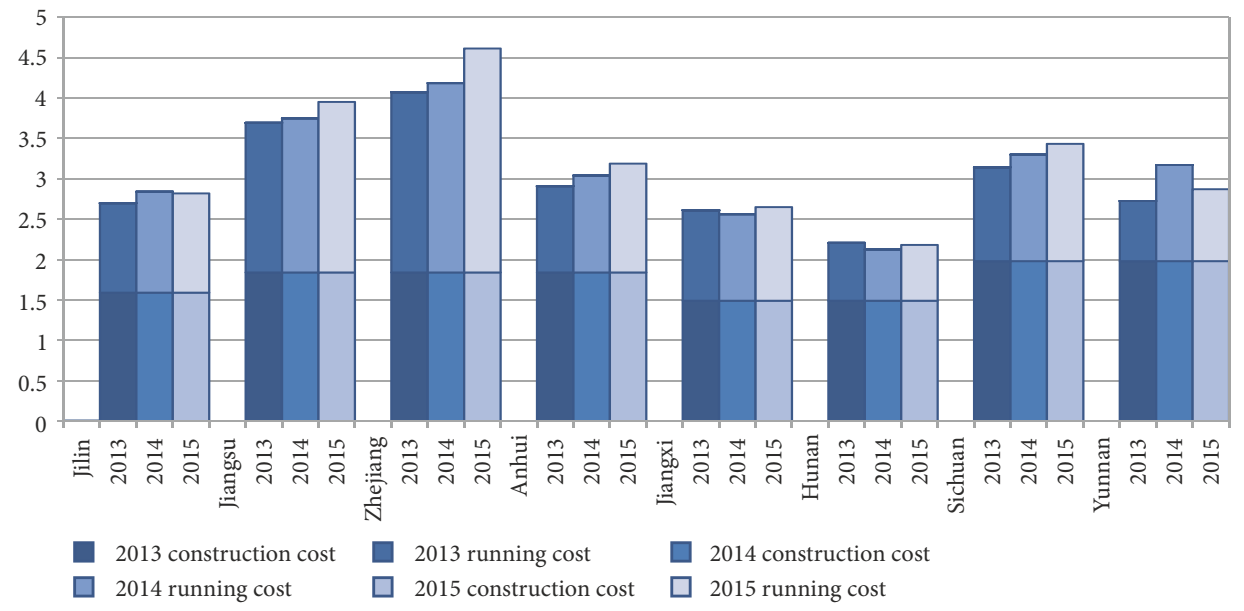

Figure 9. Average cost of industrial waste water treatment

Table 4. Discharged and treatment of industrial waste water

\begin{tabular}{|l|c|c|c|c|c|c|}
\hline \multirow{2}{*}{ Region } & \multicolumn{2}{|c|}{2013} & \multicolumn{2}{c|}{2014} & \multicolumn{2}{c|}{2015} \\
\cline { 2 - 7 } & $\begin{array}{c}\text { Waste water } \\
\text { discharged } \\
\text { (10000 tons) }\end{array}$ & $\begin{array}{c}\text { Waste water } \\
\text { treated } \\
(10000 \text { tons })\end{array}$ & $\begin{array}{c}\text { Waste water } \\
\text { discharged } \\
(10000 \text { tons })\end{array}$ & $\begin{array}{c}\text { Waste water } \\
\text { treated } \\
(10000 \text { tons })\end{array}$ & $\begin{array}{c}\text { Waste water } \\
\text { discharged } \\
(10000 \text { tons })\end{array}$ & $\begin{array}{c}\text { Waste water } \\
\text { treated } \\
(10000 \text { tons })\end{array}$ \\
\hline Jilin & 42656 & 61806 & 42192 & 52798 & 38772 & 48128 \\
\hline Jiangsu & 220559 & 395899 & 204890 & 407334 & 206427 & 418384 \\
\hline Zhejiang & 163674 & 256857 & 149380 & 255326 & 147353 & 226421 \\
\hline Anhui & 70972 & 203173 & 69580 & 191790 & 71436 & 191980 \\
\hline Jiangxi & 68230 & 167422 & 64856 & 165078 & 76412 & 173597 \\
\hline Hunan & 92311 & 263399 & 82271 & 253637 & 76888 & 253798 \\
\hline Sichuan & 64864 & 171902 & 67577 & 183402 & 71647 & 145827 \\
\hline Yunnan & 41844 & 174187 & 40443 & 141438 & 45933 & 128343 \\
\hline
\end{tabular}

Table 5. Price of industrial water

\begin{tabular}{|l|c|c|c|c|}
\hline \multicolumn{2}{|c|}{} & $\begin{array}{c}\text { Basic water price } \\
\text { (yuan/cubic metre) }\end{array}$ & $\begin{array}{c}\text { Sewage treatment fees } \\
\text { (yuan/cubic metre) }\end{array}$ & $\begin{array}{c}\text { Total } \\
\text { (yuan/cubic metre) }\end{array}$ \\
\hline Jilin & 2016 & 2.18 & 0.8 & 2.98 \\
\hline \multirow{3}{*}{ jiangsu } & 2011 & 1.5 & 1 & 2.5 \\
\cline { 2 - 5 } & 2016 & 1.85 & 1.15 & 3 \\
\hline Zhejiang & 2016 & 1.75 & 1.8 & 3.55 \\
\hline Anhui & 2016 & 1.9 & 0.7 & 2.6 \\
\hline Jiangxi & 2016 & 2.37 & 0.8 & 3.17 \\
\hline \multirow{2}{*}{ Hunan } & 2011 & 1.4 & 0.8 & 2.2 \\
\cline { 2 - 5 } & 2016 & 2.4 & 1.05 & 3.45 \\
\hline \multirow{2}{*}{ Sichuan } & 2014 & 2.9 & 1.4 & 4.3 \\
\cline { 2 - 5 } & 2016 & 4.4 & 1.4 & 5.8 \\
\hline Yunnan & 2016 & 4.35 & 1.25 & 5.6 \\
\hline
\end{tabular}


If the polluters do not pay the sewage treatment fee, they should pay the sewage charge in accordance with the type and quantity of pollutants discharged. Table 6 shows the discharged and treated pollutants from industrial waste water in Hunan Province in 2013.

If the industrial waste water is directly discharged, then the concentration and total volume of pollutants discharged exceeded the standard. In accordance with regulations, such action should be levied three times the sewage charges. In accordance with the levy standards of 0.7 yuan/pollution equivalent, the average sewage charge in Hunan Province in 2013 was 0.67 yuan/ton. Similarly, we can obtain the average sewage charges from 2011 to 2015 in the selected regions, and Figure 10 shows the results.

Table 6. Discharged and treated pollutants from industrial waste water

\begin{tabular}{|l|c|c|c|}
\hline & $\begin{array}{c}\text { Discharged volume } \\
\text { (ton) }\end{array}$ & $\begin{array}{c}\text { Treated volume } \\
\text { (ton) }\end{array}$ & $\begin{array}{c}\text { Pollution equivalent value } \\
\text { (kg) }\end{array}$ \\
\hline Chemical Oxygen Demand & 140688.7 & 470648.6 & 1 \\
\hline Ammona Nitrogen & 23046.5 & 35803.2 & 0.8 \\
\hline Petroleum & 575.4 & 5100 & 0.1 \\
\hline Volatile Phenols & 17.9 & 971.8 & 0.08 \\
\hline Cyanide & 10.2 & 203.2 & 0.05 \\
\hline Plumbum & 24.2 & 365.92 & 0.025 \\
\hline Mercury & 0.22 & 2.57 & 0.0005 \\
\hline Cadmium & 6.7 & 156.54 & 0.005 \\
\hline Hexavalent Chromium & 1 & 32.63 & 0.02 \\
\hline Total Chromium & 11.26 & 39.46 & 0.04 \\
\hline Arsenic & 42.52 & 297.63 & 0.02 \\
\hline
\end{tabular}

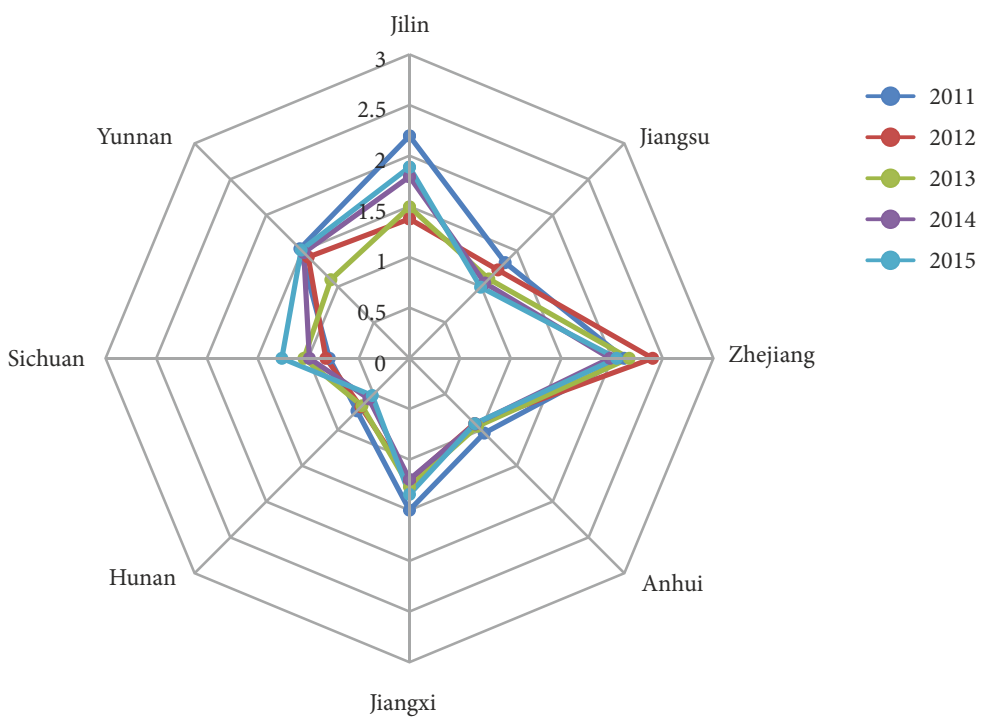

Figure 10. Average sewage charges 


\subsection{Results and discussion}

First, we must select the applicable model of the selected regions to determine the relationship between $C_{2}$ and $\beta P_{N}$. Table 7 shows the unit processing costs and the critical price of no resource return model in the selected regions.

Table 7. $C_{2}$ and $\beta P_{N}$ in the selected regions

\begin{tabular}{|l|c|c|c|c|c|c|c|c|c|c|}
\hline \multirow{2}{*}{} & \multicolumn{2}{|c|}{2011} & \multicolumn{2}{c|}{2012} & \multicolumn{2}{c|}{2013} & \multicolumn{2}{c|}{2014} & \multicolumn{2}{c|}{2015} \\
\cline { 2 - 11 } & $\beta P_{N}$ & $C_{2}$ & $\beta P_{N}$ & $C_{2}$ & $\beta P_{N}$ & $C_{2}$ & $\beta P_{N}$ & $C_{2}$ & $\beta P_{N}$ & $C_{2}$ \\
\hline Jilin & 1.076 & 2.552 & 1.634 & 2.521 & 0.923 & 2.698 & 0.599 & 2.840 & 0.579 & 2.818 \\
\hline Jiangsu & 0.976 & 3.610 & 1.253 & 4.224 & 1.329 & 3.692 & 1.491 & 3.748 & 1.520 & 3.951 \\
\hline Zhejiang & 1.424 & 3.373 & 1.123 & 3.805 & 1.288 & 4.071 & 1.473 & 4.184 & 1.240 & 4.612 \\
\hline Anhui & 1.738 & 2.702 & 1.754 & 2.852 & 1.692 & 2.908 & 1.657 & 3.040 & 1.633 & 3.187 \\
\hline Jiangxi & 1.544 & 2.544 & 1.943 & 2.394 & 1.878 & 2.610 & 1.925 & 2.561 & 1.775 & 2.649 \\
\hline Hunan & 1.307 & 2.607 & 2.207 & 2.153 & 2.241 & 2.206 & 2.331 & 2.125 & 2.405 & 2.180 \\
\hline Sichuan & 3.092 & 4.154 & 2.849 & 3.351 & 2.677 & 3.142 & 2.716 & 3.299 & 2.950 & 3.432 \\
\hline Yunnan & 3.778 & 2.818 & 3.932 & 2.823 & 4.255 & 2.724 & 3.999 & 3.170 & 3.596 & 2.870 \\
\hline
\end{tabular}

As shown in Table 7, in addition to Yunnan and Hunan Provinces, the rest of the selected regions all meet the condition $C_{2}>\beta P_{N}$. With the shortage of water resources in Yunnan Province, its basic water price is considerably higher than that in the regions with abundant water resources. However, at present, the industrial waste water treatment plants in Yunnan and Hunan Provinces still cannot provide free sewage treatment for polluters. Therefore, the no resource return model is unsuitable for industrial waste water circulation in these two provinces. The resource return model is inapplicable to these two provinces, because they do not satisfy $C_{2} \leq \frac{\beta}{\beta+1} P_{N}$. Therefore, the eight selected regions are only the ones with the government participation to complete the cycle of industrial waste water.

Then, we compare the unit recycling price $P_{2}$ and pollution tax $t_{1}$. At present, China has not yet formally imposed a specialised environmental protection tax. To control environmental pollution, the Chinese government charges a fee to the polluters on the basis of the type and amount of discharge pollutants. Therefore, in this case, we use the sewage charges to replace environmental tax. In addition the unit recycling price is the sewage treatment fee. Table 8 shows the sewage treatment fees and sewage charges in the selected regions.

As shown in Table 8, all regions meet the condition $t_{1} \geq P_{2}$. Thus, the polluters will opt to discharge the sewage into the sewage centralised treatment facility rather than directly to the natural environment. The industrial waste water discharged by various industries has a large difference in pollutants, and the sewage charges of some industries will be less than the sewage treatment fee. However, as an entire, most industries in the selected regions meet the condition $t_{1} \geq P_{2}$.

Finally, we analyse whether the current policy is appropriate. We obtain the critical tax rate $t_{1}^{*}$ of selected regions on the basis of Eq. (10). Table 9 shows the results. 
Table 8. Sewage treatment fees and sewage charges

\begin{tabular}{|l|c|c|c|c|c|c|c|c|c|c|}
\hline \multirow{2}{*}{} & \multicolumn{2}{|c|}{2011} & \multicolumn{2}{c|}{2012} & \multicolumn{2}{c|}{2013} & \multicolumn{2}{c|}{2014} & \multicolumn{2}{c|}{2015} \\
\cline { 2 - 12 } & $P_{2}$ & $t_{1}$ & $P_{2}$ & $t_{1}$ & $P_{2}$ & $t_{1}$ & $P_{2}$ & $t_{1}$ & $P_{2}$ & $t_{1}$ \\
\hline Jilin & 0.800 & 2.195 & 0.800 & 1.376 & 0.800 & 1.494 & 0.800 & 1.793 & 0.800 & 1.887 \\
\hline Jiangsu & 1.000 & 1.336 & 1.150 & 1.234 & 1.150 & 1.108 & 1.150 & 1.051 & 1.150 & 0.993 \\
\hline Zhejiang & 1.800 & 2.120 & 1.800 & 2.401 & 1.800 & 2.169 & 1.800 & 1.980 & 1.800 & 2.045 \\
\hline Anhui & 0.700 & 1.044 & 0.700 & 0.910 & 0.700 & 0.949 & 0.700 & 0.918 & 0.700 & 0.912 \\
\hline Jiangxi & 0.800 & 1.499 & 0.800 & 1.204 & 0.800 & 1.270 & 0.800 & 1.195 & 0.800 & 1.343 \\
\hline Hunan & 0.800 & 0.733 & 1.050 & 0.678 & 1.050 & 0.663 & 1.050 & 0.566 & 1.050 & 0.519 \\
\hline Sichuan & 1.400 & 0.791 & 1.400 & 0.825 & 1.400 & 1.042 & 1.400 & 0.988 & 1.400 & 1.260 \\
\hline Yunnan & 1.250 & 1.530 & 1.250 & 1.413 & 1.250 & 1.097 & 1.250 & 1.475 & 1.250 & 1.512 \\
\hline
\end{tabular}

Table 9. Critical tax rate of selected regions

\begin{tabular}{|c|c|c|c|c|c|c|c|c|}
\hline & Jilin & Jiangsu & Zhejiang & Anhui & Jiangxi & Hunan & Sichuan & Yunnan \\
\hline 2011 & 4.884 & 7.745 & 6.662 & 2.142 & 2.851 & 2.987 & 2.876 & -0.172 \\
\hline 2012 & 2.416 & 8.261 & 10.282 & 2.328 & 1.536 & 0.966 & 2.157 & -0.33 \\
\hline 2013 & 6.527 & 6.486 & 9.471 & 2.57 & 2.035 & 0.996 & 2.145 & -0.764 \\
\hline 2014 & 11.957 & 5.691 & 8.333 & 2.87 & 1.848 & 0.745 & 2.324 & 0.089 \\
\hline 2015 & 12.318 & 5.948 & 11.458 & 3.176 & 2.361 & 0.728 & 2.346 & 0.12 \\
\hline
\end{tabular}

As shown in Table 9, in addition to Yunnan Province, the sewage charges in the rest of selected regions are lower than the critical tax rates. The cost of sewage treatment in most regions of China remains high due to continuous improvement of water quality standards, relatively backward sewage treatment technology and many other reasons. By combining Table 7 with Table 8, the sewage treatment fee in China covers only the running cost of the sewage treatment plant, but not all the treatment costs of the sewage treatment (Tan et al., 2015). If no measures are implemented, then sewage treatment plants in these regions will be unable to make ends meet.

At present, the Chinese government follows the approach of local financial subsidies to compensate for the economic losses of sewage treatment plants. However, sewage treatment plants still fail to receive sufficient subsidies and are facing bankruptcy. In the long run, the use of a subsidy policy will aggravate the burden of local finance and not fundamentally improve the difficult situation of sewage circulation. On the basis of the model proposed in this paper, China should adjust its existing policies to meet the critical conditions of the cyclic model in the short term. In the long run, China should focus on improving the level of technology and improving the system, such that the industrial waste water circulation can transform from government participation to self-regulation.

The Chinese government has performed adjustments in recent years. From 2016 onwards, China has adjusted the sewage charge of main pollutants in industrial waste water from 0.7 yuan/pollution equivalent to 1.4 yuan/pollution equivalent. Figure 11 shows the difference between the sewage charges before and after the adjustment and the critical tax rate by using the 2015 data as an example. 
The adjustment of this policy narrows the gap between the sewage charges and critical tax rates in most regions. After the adjustment, the sewage charges in Anhui, Jiangxi and Hunan Provinces can satisfy $t_{1}>t_{1}^{*}$, i.e. the actual sewage charge is greater than the critical tax rate. In addition, various regions have performed adjustments in accordance with their conditions. For example, from 2016 onwards, Hunan Province has adjusted the expense of sewage processing of process water from 1.05 yuan/cubic metre to 1.4 yuan/cubic metre. Figure 12 presents the difference between the sewage treatment fees and unit processing costs.

As shown in Figure 12, the difference between the sewage treatment fees and unit processing costs has significantly reduced. This adjustment can effectively reduce the pressure on local finance. As the unit processing cost remains greater than the sewage treatment fee, the subsidy policy remains necessary.

From such analysis, the current development of industrial waste water circulation and related policies are in line with the results of the proposed model. The proposed model can efficiently predict the development trend and provide suggestions for the corresponding CE development. The results fully illustrate the validity and feasibility of the model proposed in this paper.

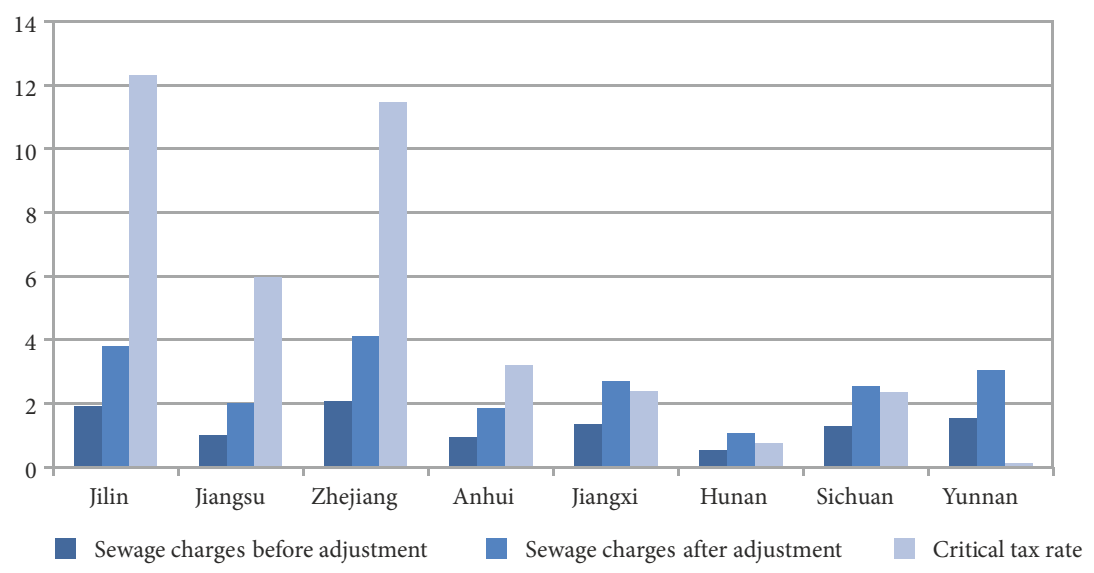

Figure 11. Sewage charges before and after the adjustment

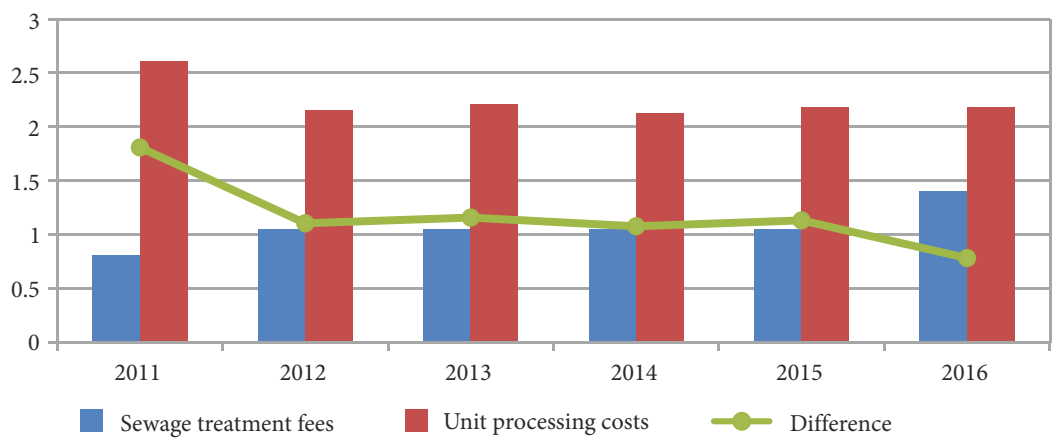

Figure 12. Sewage treatment fees and unit processing costs 


\section{Conclusions}

This study established a model for analysing CE from the perspective of resource flow. Marginal and equilibrium analyses were used to obtain the boundary conditions for the establishment of $\mathrm{CE}$ models with different resource flows. By comparing the differences among various models, this study explored how different resource flows will affect the CE system. Finally, we investigated the industrial waste water circulation of some provinces in China to illustrate the feasibility and effectiveness of the proposed model. The main conclusions of this paper are summarised as follows.

This study constructed two models of anarchic participation on the basis of whether the waste management department returns the recycling resource after disposal or not. In the absence of government participation, the circulatory system is established only when the production department discharges waste to the waste management department without economic loss. Under the premise that the circulatory system can operate autonomously, this work obtained the boundary conditions of government participation in the process of CE transitioning from external interference to autonomous operation. This boundary condition is only related to three factors, namely, unit processing cost, disposal return rate and natural resource price. Then, this study constructed two models with government participation. Aiming at maintaining the circulatory system without adding extra burden to the production department, the boundary of government taxation is obtained through equilibrium analysis. The optimal value of government taxation is equal to the difference between unit effective cost and natural resource price. At last, comparing these models, the government participation boundary of the no recycling resource return model is more lenient than that of the recycling resource return model. The significance of this result is that when the time is right, large enterprises can establish their internal waste management department to replace the centralised processing mode in accordance with their needs. Although the resource flow has a significant effect on the boundaries of government participation, those of government taxation are not affected.

The results suggested that in the early stage of CE development, unit processing cost is generally greater than the product of unit natural resource price and disposal return rate, at which time the circulatory system cannot operate on its own. Therefore, the government should impose a certain amount of pollution tax to maintain the circulatory system. The obtained optimal value of government taxation is the minimum value for satisfying the boundary, which can not only maintain the circulatory system but also maximise the economic benefits. In the initial stage, because the unit processing cost and disposal return rate are difficult to change in the short term, the government can approach the boundary conditions of government participation by raising the price of natural resources, such as the example of industrial waste water circulation in China. However, such strategy is unsuitable for frequent or large-scale adjustment. In addition, the government can indirectly reduce unit processing cost by granting subsidies (Fang \& Zeng, 2007). The advantage of this measure is that the production department will not be affected, but similar to other subsidies, its effect is often difficult to guarantee due to the difficulties of supervision and implementation (Lim, Wang, \& Zeng, 2018). Therefore, to achieve the long-term healthy development of the circulatory system, the government should still focus on increasing the disposal return rate and reducing 
the unit processing cost. When the relationship among unit processing cost, disposal return rate and natural resource price have changed, the government should adjusted tax revenue in accordance with the development situation to maximise the economic benefits of the circulatory system while maintaining its operation. When the optimal value of government taxation is 0 , the quantitative relationship among unit processing cost, disposal return rate and natural resource price satisfies the boundary value of government participation. Hence, the circulatory system can operate independently and no longer needs the participation of the government in tax collection.

Therefore, when government participation aims to change the circulatory system to spontaneous operation, its policy should be able to bring the actual situation close to the boundary conditions. In the short run, the government can achieve its goal by increasing natural resource prices or subsidies to reduce unit processing costs. In the long run, the government should focus on improving the disposal return rate and reducing the unit processing cost through technological innovation. In the example of the industrial waste water circulation in China, some provinces such as Jiangsu province, narrowed the gap between the actual situation and the boundary conditions by increasing the unit cost of industrial water in the early stage, but this adjustment has not been frequently used.

When the government has not established a circulatory system or is in the early stages of the development of the circulatory system, the government should formulate corresponding taxes on the basis of the relationship among unit processing cost, disposal return rate and natural resource price. Subsequently, the tax revenue is adjusted in accordance with the development situation to maximise the economic benefits of the circulatory system while maintaining its operation. Eventually, when the circulatory system does not require government taxation to maintain operations, the government can cancel the corresponding tax order, and the circulation system can operate independently. In the example of this paper, the Chinese government's two adjustments to the sewage tax have brought the actual situation close to the boundary conditions.

For governments around the world, technologies related to $\mathrm{CE}$ are still innovating. It is difficult to achieve high resource recycling rate and low processing cost at the same time in the prior art. Some regions or some resources even have low resource recycling rates and high processing costs. Under this circumstance, many countries can only establish corresponding circulation paths in some areas, but it is difficult to establish an effective circulation system at the macro level. As a new model to replace the traditional linear development model, CE has fallen into a bottleneck. This paper under the existing situation of CE development is to analyse the corresponding behaviours of the waste management department, production department and government. The results obtained can guide the policy decisions of governments at all stages of the $\mathrm{CE}$ development. The conclusions obtained can evaluate the existing policies related to the $\mathrm{CE}$ and provide an important reference for future policy adjustments.

In summary, this paper redefines $\mathrm{CE}$ from the perspective of resource flows. On this basis, different CE models are constructed according to the different recycling paths of the waste resources. Different from the existing research, this paper explores the role of the government in the development of circular economy when the circulatory system has not been established or established in the early stage from the perspective of resource flow. On the one hand, the system optimal pollution tax rate and equilibrium solution of each model are 
obtained through a static analysis of the model. On the other hand, the conditions that render the government participation models effective are obtained through a comparative analysis of the model. The results obtained explain the motivation of the government for formulating and adjusting CE policies from a new perspective. The results of this study can predict the future development trend and provide proposals to the countries that have not yet developed CE to build their recycling system. Furthermore, the proposed CE can provide the standard of policy adjustment for the countries that have already implemented the circulation policy.

\section{Acknowledgements}

This work was supported by the National Natural Science Foundation of China (Nos. 71871228 \& 71473076).

\section{References}

Andersen, M. S. (2007). An introductory note on the environmental economics of the circular economy. Sustainability Science, 2(1), 133-140. https://doi.org/10.1007/s11625-006-0013-6

Birat, J. P. (2015). Life-cycle assessment, resource efficiency and recycling. Metallurgical Research \& Technology, 112(2), 2271-3646. https://doi.org/10.1051/metal/2015009

Bocken, N. M. P., de Pauw, I., Bakker, C., \& van der Grinten, B. (2016). Product design and business model strategies for a circular economy. Journal of Industrial and Production Engineering, 33(5), 308-320. https://doi.org/10.1080/21681015.2016.1172124

Boulding, K. E. (1966). The economics of the coming spaceship earth. Environmental Quality Issues in a Growing Economy.

Castellani, V., Sala, S., \& Mirabella, N. (2015). Beyond the throwaway society: A life cycle-based assessment of the environmental benefit of reuse. Integrated Environmental Assessment and Management, 11(3), 373-382. https://doi.org/10.1002/ieam.1614

da Silva, C. L. (2018). Proposal of a dynamic model to evaluate public policies for the circular economy: Scenarios applied to the municipality of Curitiba. Waste Management, 78, 456-466. https://doi.org/10.1016/j.wasman.2018.06.007

Dong, L., Fujita, T., Dai, M., Geng, Y., Ren, J., Fujii, M., Wang, Y., \& Ohnishi, S. (2016). Towards preventative eco-industrial development: An industrial and urban symbiosis case in one typical industrial city in China. Journal of Cleaner Production, 114, 387-400.

https://doi.org/10.1016/j.jclepro.2015.05.015

Fang, Y., \& Zeng, Y. (2007). Balancing energy and environment: The effect and perspective of management instruments in China. Energy, 32(12), 2247-2261. https://doi.org/10.1016/j.energy.2007.07.016

Franco, M .A. (2017). Circular economy at the micro level: A dynamic view of incumbents' struggles and challenges in the textile industry. Journal of Cleaner Production, 168, 833-845. https://doi.org/10.1016/j.jclepro.2017.09.056

Geissdoerfer, M., Savaget, P., Bocken, N. M. P., \& Hultink, E. J. (2017). The Circular Economy - A new sustainability paradigm? Journal of Cleaner Production, 143, 757-768. https://doi.org/10.1016/j.jclepro.2016.12.048

Geng, Y., Fu, J., Sarkis, J., \& Xue, B. (2012). Towards a national circular economy indicator system in China: An evaluation and critical analysis. Journal of Cleaner Production, 23(1), 216-224.

https://doi.org/10.1016/j.jclepro.2011.07.005 
Geng, Y., Wang, M., Sarkis, J., Xue, B., Zhang, L., Fujita, T., Yu, X., Ren, W., Zhang, L., \& Dong, H. (2014). Spatial-temporal patterns and driving factors for industrial wastewater emission in China. Journal of Cleaner Production, 76, 116-124. https://doi.org/10.1016/j.jclepro.2014.04.047

Geng, Y., Zhang, P., Cote, R. P., \& Qi, Y. (2008). Evaluating the applicability of the Chinese eco-industrial park standard in two industrial zones. The International Journal of Sustainable Development \& World Ecology, 15(6), 543-552. https://doi.org/10.1080/13504500809469850

Genovese, A., Acquaye, A. A., Figueroa, A., \& Koh, S. C. L. (2017). Sustainable supply chain management and the transition towards a circular economy: Evidence and some applications. Omega, 66, 344-357. https://doi.org/10.1016/j.omega.2015.05.015

George, D. A. R., Lin, B. C.-a., \& Chen, Y. (2015). A circular economy model of economic growth. Environmental Modelling \& Software, 73, 60-63. https://doi.org/10.1016/j.envsoft.2015.06.014

Ghisellini, P., Cialani, C., \& Ulgiati, S. (2016). A review on circular economy: The expected transition to a balanced interplay of environmental and economic systems. Journal of Cleaner Production, 15(114), 11-32. https://doi.org/10.1016/j.jclepro.2015.09.007

Guo, B., Geng, Y., Ren, J., Zhu, L., Liu, Y., \& Sterr, T. (2017a). Comparative assessment of circular economy development in China's four megacities: The case of Beijing, Chongqing, Shanghai and Urumqi. Journal of Cleaner Production, 162, 234-246. https://doi.org/10.1016/j.jclepro.2017.06.061

Guo, B., Geng, Y., Sterr, T., Zhu, Q., \& Liu, Y. (2017b). Investigating public awareness on circular economy in western China: A case of Urumqi Midong. Journal of Cleaner Production, 142(Part 4), 2177-2186. https://doi.org/10.1016/j.jclepro.2016.11.063

Haas, W., Krausmann, F., Wiedenhofer, D., \& Heinz, M. (2015). How circular is the global economy?: An assessment of material flows, waste production, and recycling in the European Union and the world in 2005. Journal of Industrial Ecology, 19(5), 765-777. https://doi.org/10.1111/jiec.12244

Haupt, M., Vadenbo, C., \& Hellweg, S. (2016). Do we have the right performance indicators for the circular economy?: Insight into the Swiss waste management system. Journal of Industrial Ecology, 21(3), 615-627. https://doi.org/10.1111/jiec.12506

Hu, J., Xiao, Z., Zhou, R., Deng, W., Wang, M., \& Ma, S. (2011). Ecological utilization of leather tannery waste with circular economy model. Journal of Cleaner Production, 19(2), 221-228. https://doi.org/10.1016/j.jclepro.2010.09.018

Huang, K., Guo, J., \& Xu, Z. (2009). Recycling of waste printed circuit boards: A review of current technologies and treatment status in China. Journal of Hazardous Materials, 164(2), 399-408. https://doi.org/10.1016/j.jhazmat.2008.08.051

Huysman, S., De Schaepmeester, J., Ragaert, K., Dewulf, J., \& De Meester, S. (2017). Performance indicators for a circular economy: A case study on post-industrial plastic waste. Resources, Conservation and Recycling, 120, 46-54. https://doi.org/10.1016/j.resconrec.2017.01.013

Mckinsey Global Institute. (2011). Urban world: mapping the economic power of cities.

Kalathil, D., Wu, C., Poolla, K., \& Varaiya, P. (2017). The sharing economy for the electricity storage. IEEE Transactions on Smart Grid, 10(1), 556-567. https://doi.org/10.1109/TSG.2017.2748519

Kallis, G. (2011). In defence of degrowth. Ecological Economics, 70(5), 873-880. https://doi.org/10.1016/j. ecolecon.2010.12.007

Kurzban, R., \& Houser, D. (2001). Individual differences in cooperation in a circular public goods game. European Journal of Personality, 15(S1), S37-S52. https://doi.org/10.1002/per.420

Leslie, H. A., Leonards, P. E. G., Brandsma, S. H., Boer, J. D., \& Jonkers, N. (2016). Propelling plastics into the circular economy - weeding out the toxics first. Environment International, 94, 230-234. https://doi.org/10.1016/j.envint.2016.05.012

Lim, C. Y., Wang, J., \& Zeng, C. (2018). China's "Mercantilist" government subsidies, the cost of debt and firm performance. Journal of Banking \& Finance, 86, 37-52.

https://doi.org/10.1016/j.jbankfin.2017.09.004 
Liu, L., Liang, Y., Song, Q., \& Li, J. (2017). A review of waste prevention through 3R under the concept of circular economy in China. Journal of Material Cycles and Waste Management, 19(4), 1314-1323. https://doi.org/10.1007/s10163-017-0606-4

Liu, Z., Adams, M., Cote, R. P., Chen, Q., Wu, R., Wen, Z., Liu, W., \& Dong, L. (2018). How does circular economy respond to greenhouse gas emissions reduction: An analysis of Chinese plastic recycling industries. Renewable and Sustainable Energy Reviews, 91, 1162-1169. https://doi.org/10.1016/j.rser.2018.04.038

Marra, A., Mazzocchitti, M., \& Sarra, A. (2018). Knowledge sharing and scientific cooperation in the design of research-based policies: The case of the circular economy. Journal of Cleaner Production, 194, 800-812. https://doi.org/10.1016/j.jclepro.2018.05.164

McDowall, W., Geng, Y., Huang, B., Barteková, E., Bleischwitz, R., Türkeli, S., Kemp, R., \& Doménech, T. (2017). Circular economy policies in China and Europe. Journal of Industrial Ecology, 21(3), 651-661. https://doi.org/10.1111/jiec.12597

Namany, S., Al-Ansari, T., \& Govindan, R. (2018). Integrated techno-economic optimization for the design and operations of energy, water and food nexus systems constrained as non-cooperative games. In M. R. Eden, M. G. Ierapetritou, \& G. P. Towler, Computer aided chemical engineering (Vol. 44, pp. 1003-1008). Elsevier. https://doi.org/10.1016/B978-0-444-64241-7.50162-2

Nizami, A. S., Rehan, M., Waqas, M., Naqvi, M., Ouda, O. K. M., Shahzad, K., Miandad, R., Khan, M. Z., Syamsiro, M., Ismail, I. M. I., \& Pant, D. (2017). Waste biorefineries: Enabling circular economies in developing countries. Bioresource Technology, 241, 1101-1117. https://doi.org/10.1016/j.biortech.2017.05.097

Pan, S. Y., Du, M. A., Huang, I. T., Liu, I. H., Chang, E. E., \& Chiang, P.-C. (2015). Strategies on implementation of waste-to-energy (WTE) supply chain for circular economy system: a review. Journal of Cleaner Production, 108, 409-421. https://doi.org/10.1016/j.jclepro.2015.06.124

Pigou, A. C. (2014). The economics of welfare. Macmillan and Co, limited.

Pitt, J., \& Heinemeyer, C. (2015). Introducing ideas of a circular economy. Sense Publishers. https://doi.org/10.1007/978-94-6209-938-8_16

Pomponi, F., \& Moncaster, A. (2017). Circular economy for the built environment: A research framework. Journal of Cleaner Production, 143, 710-718. https://doi.org/10.1016/j.jclepro.2016.12.055

Preston, F. (2012). A global redesign? Shaping the circular economy. Retrieved from https://www.chathamhouse.org/publications/papers/view/182376

Ross, D. G. (2018). Using cooperative game theory to contribute to strategy research. Strategic Management Journal, 39(11), 2859-2876. https://doi.org/10.1002/smj.2936

Schneider, F., Kallis, G., \& Martinez-Alier, J. (2010). Crisis or opportunity? Economic degrowth for social equity and ecological sustainability. Introduction to this special issue. Journal of Cleaner Production, 18(6), 511-518. https://doi.org/10.1016/j.jclepro.2010.01.014

Shen, K., \& Wang, J. (2018). Z-VIKOR method based on a new comprehensive weighted distance measure of Z-number and its application. IEEE Transactions on Fuzzy Systems, 26(6), 3232-3245. https://doi.org/10.1109/TFUZZ.2018.2816581

Shubik, M. (1981). Game theory models and methods in political economy. Handbook of Mathematical Economics, 1, 285-330. https://doi.org/10.1016/S1573-4382(81)01011-4

Sousa-Zomer, T. T., Magalhães, L., Zancul, E., Campos, L .M., \& Cauchick-Miguel, P. A. (2018). Cleaner production as an antecedent for circular economy paradigm shift at the micro-level: Evidence from a home appliance manufacturer. Journal of Cleaner Production, 185, 740-748.

https://doi.org/10.1016/j.jclepro.2018.03.006

Su, B., Heshmati, A., Geng, Y., \& Yu, X. (2013). A review of the circular economy in China: moving from rhetoric to implementation. Journal of Cleaner Production, 42, 215-227.

https://doi.org/10.1016/j.jclepro.2012.11.020 
Sun, J., Li, G., \& Wang, Z. (2019). Technology heterogeneity and efficiency of China's circular economic systems: A game meta-frontier DEA approach. Resources, Conservation and Recycling, 146, 337-347. https://doi.org/10.1016/j.resconrec.2019.03.046

Tan, C., Liu, Z., Wu, D. D., \& Chen, X. (2018). Cournot game with incomplete information based on rank-dependent utility theory under a fuzzy environment. International Journal of Production Research, 56(5), 1789-1805. https://doi.org/10.1080/00207543.2015.1131865

Tan, X., Shi, L., Chen, Z., Li, T., Ma, Z., Zheng, X., \& Cheng, R. (2015). Cost analysis of the municipal wastewater treatment plant operation based on 227 samples in China. Water \& Wastewater Engineering.

Tukker, A. (2015). Product services for a resource-efficient and circular economy - a review. Journal of Cleaner Production, 97, 76-91. https://doi.org/10.1016/j.jclepro.2013.11.049

van der Ploeg, F., \& de Zeeuw, A. (2016). Non-cooperative and cooperative responses to climate catastrophes in the global economy: A North-South perspective. Environmental and Resource Economics, 65(3), 519-540. https://doi.org/10.1007/s10640-016-0037-z

Wübbeke, J., \& Heroth, T. (2014). Challenges and political solutions for steel recycling in China. Resources, Conservation and Recycling, 87, 1-7. https://doi.org/10.1016/j.resconrec.2014.03.004

Wei-guang, Z. J. G. L., \& Yue, Z. (2011). Current situation and development prospects of scrap processing equipment in China [J]. Iron \& Steel Scrap of China, 4.

Wen, Z., \& Meng, X. (2015). Quantitative assessment of industrial symbiosis for the promotion of circular economy: a case study of the printed circuit boards industry in China's Suzhou New District. Journal of Cleaner Production, 90, 211-219. https://doi.org/10.1016/j.jclepro.2014.03.041

Wenxia, L. I. U., Yundi, L., \& Tianyang, Z. (2015). Cooperative game based capacity planning model for wind power in low-carbon economy. AEPS, 39(19), 68-74.

Whicher, A., Harris, C., Beverley, K., \& Swiatek, P. (2018). Design for circular economy: Developing an action plan for Scotland. Journal of Cleaner Production, 172, 3237-3248. https://doi.org/10.1016/j.jclepro.2017.11.009

Winans, K., Kendall, A., \& Deng, H. (2017). The history and current applications of the circular economy concept. Renewable and Sustainable Energy Reviews, 68, 825-833. https://doi.org/10.1016/j.rser.2016.09.123

Witjes, S., \& Lozano, R. (2016). Towards a more Circular Economy: Proposing a framework linking sustainable public procurement and sustainable business models. Resources Conservation \& Recycling, 112, 37-44. https://doi.org/10.1016/j.resconrec.2016.04.015

Wong, J. K. W., \& Zhou, J. (2015). Enhancing environmental sustainability over building life cycles through green BIM: A review. Automation in Construction, 57, 156-165. https://doi.org/10.1016/j.autcon.2015.06.003

Wu, H. Q., Shi, Y., Xia, Q., \& Zhu, W. D. (2014). Effectiveness of the policy of circular economy in China: A DEA-based analysis for the period of 11th five-year-plan. Resources, Conservation and Recycling, 83, 163-175. https://doi.org/10.1016/j.resconrec.2013.10.003

Yong, R. (2007). The circular economy in China. Journal of Material Cycles and Waste Management, 9(2), 121-129. https://doi.org/10.1007/s10163-007-0183-Z

Yuan, Z., Bi, J., \& Moriguichi, Y. (2010). The Circular Economy: A new development strategy in China. Journal of Industrial Ecology, 10(1-2), 4-8. https://doi.org/10.1162/108819806775545321

Zhang, C. T., \& Liu, L. P. (2013). Research on coordination mechanism in three-level green supply chain under non-cooperative game. Applied Mathematical Modelling, 37(5), 3369-3379. https://doi.org/10.1016/j.apm.2012.08.006

Zhao, Y., Yang, W., Song, W., Huang, S., Nie, X., Tuo, J., Piao, Z., \& Yan, H. (2018). A capacity planning method for wind power based on cooperative game theory in carbon trading process. In 2018 2nd IEEE Conference on Energy Internet and Energy System Integration (EI2) (pp. 1-6). https://doi.org/10.1109/EI2.2018.8582327 